\title{
THE ACTION OF PITUITARY EXTRACT ON THE HEART OF THE UNANESTHETIZED DOG
}

By WILLIAM H. RESNIK AND E. M. K. GEILING

(From the Cardiographic Laboratory of the Johns Hopkins Hospital and from the Department of Pharmacology of the Johns Hopkins University)

(Received for publication, October 22, 1924)

\section{INTRODUCTION}

Although the effect of the extract of the posterior lobe of the pituitary gland upon the mammalian heart has been studied by a number of investigators, the results have not been uniform. In the first study. of the action of pituitary extracts, Oliver and Schäfer (1895) found that with the vagi intact no inhibition of the heart took place, but that with the vagi cut there was a slight diminution in heart rate. Howell (1898) obtained a definite slowing with the vagi intact. When the vagi were cut or under the influence of atropine, a slowing of cardiac rate of lesser degree was observed, and he attributed the action of the drug to an influence not only on the cardio-inhibitory center but also to an effect on the heart muscle or the intrinsic nervous mechanism. Von Cyon (1898) obtained similar results. Hedbom (1898), Cleghorn (1899), and Dale (1909), using isolated mammalian heart preparations, found that the rate was lowered under the influence of pituitary extracts, indicating that the action was in part at least direct on the myocardium. Schäfer and Vincent (1900) observed but little slowing of the rate when the vagi were paralyzed by atropine, and occasionally no fall in rate even with the vagi intact. They concluded, however, on the basis of the experiments of Howell and of Cleghorn, that in addition to the vagal action, there must be a direct effect on the cardiac muscle. Garnier and Thaon (1906) ascribed the action wholly to an influence through the vagi, for no slowing occurred after these nerves were sectioned. Wiggers (1911) obtained slowing upon perfusion of the drug through the isolated heart; while with the heart in situ, a variety of results was seen. In 
some instances no slowing took place, in others the slowing was immediate, while in other cases the slowing was gradual in its onset. As a result of his experiments he formulated the hypothesis that the early effect was due to stimulation of the cardio-inhibitory center, and the late slowing was due to a direct action on the heart. "Either, both, or neither of these actions may follow the injection of pituitary extract, the factors determining the reaction being unknown." Claude, Porak and Routier (1913) studied the effect of pituitary extracts on the heart of the rabbit utilizing the electrocardiograph. Following administration of the drug, conduction defects and slowing of the heart were seen, with or without section of the vagi. Hecht and Nadel (1913) also used the electrocardiograph and found evidences of a direct action on the heart of unanesthetized animals. However they attributed the slowing chiefly to vagal action. Houssay (1918) as a result of his own and a study of previous experiments, concluded that the effect was in part vagal and in part direct on the myocardium.

It will be seen that although a number of the reports are contradictory, the weight of evidence favors the view that extracts of the pituitary affect the heart not only through stimulation of the cardioinhibitory center, but also through a direct action on the cardiac muscle.

\section{METHODS}

We have performed a number of experiments upon three unanesthetized dogs which had been trained to submit to procedures such as we employed. We wish to emphasize the absence of anesthesia in these experiments. Differences between the response of anesthetized and unanesthetized animals to drugs have been observed previously by Kolls and Geiling (1924), and we feel that the constancy of the results which we have obtained is in large measure due to the use of unanesthetized animals. Precautions were taken to avoid factors which might disturb the animals. They were handled by the same attendants, and the surroundings were kept as quiet and uniform as possible. The animals were rested until fairly constant heart rates were obtained before the experiments were started. ${ }^{1}$ The drugs were injected into a vein of the foreleg, each

1 The resting rates varied on different occasions from 76 to 130 . We have learned from Prof. E. K. Marshall, Jr., that with prolonged rest rates of approximately 60 may be obtained. We do not believe, however, that our results are significantly affected by our failure to secure truly basal rates. Before atropine, the slowing following the injection of pituitary extract would have been less striking, while after atropine, the results would have been unchanged. 
administration lasting five to ten seconds. The extract of the posterior lobe of the pituitary (Armour's Pituitary Liquid) was given in $1 \mathrm{cc}$. doses (except in three experiments in which 0.1 and $0.2 \mathrm{cc}$. were given). Atropine was given in doses of $1 \mathrm{mgm}$. repeated at about 15 minute intervals, and in some experiments in single doses of 5 or $6 \mathrm{mg}$. The effects were recorded with the electrocardiograph, lead III being used. Records were taken at intervals of about 15 to 30 seconds in the early periods of the experiments, and at 2 to 5 minute intervals later. In some instances, continuous records were taken during the first few minutes following the injection of the pituitary extract. Only one observation a day was made on any individual animal. The heart rates were calculated on the basis of counts made of six second periods from the electrocardiographic curves (occasionally three second periods when rapid changes were taking place), so that slight changes are somewhat exaggerated. The error in the counts is probably not more than \pm 2 per minute. The P-R intervals were occasionally difficult to measure accurately on account of the form of the curves. At times the onset of the $\mathrm{P}$ wave was not sharp, while in other records the $\mathrm{P}$ was fused with the preceding $T$ or $R$ waves.

\section{EXPERIMENTAL}

Preliminary experiments with atropine. Several observations were made upon the effect of atropine alone. When given intravenously in doses of 1 to $5 \mathrm{mg}$., the maximum vagal release was obtained within 45 seconds to one minute. One milligram was often as effective as $5 \mathrm{mg}$. in procuring a complete vagal paralysis, as judged by the failure to secure a further effect with subsequent injections of the drug in the few instances in which this was done. Our animals G1, G2, G3, weighed $11,14.5,9$ kilos respectively, so that $1 \mathrm{mg}$. amounted to $0.09,0.06$, and $0.11 \mathrm{mg}$. per kilo. Lewis, Drury, Wedd and Iliescu (1921-1922) found that 0.05 to $0.1 \mathrm{mg}$. of atropine per kilo of body weight were necessary for the complete abolition of vagal tone in anesthetized dogs. However, since the rate tended to be a little higher after 5 or $6 \mathrm{mg}$. doses than after $1 \mathrm{mg}$. doses even when this dose amounted to 0.11 $\mathrm{mg}$. per kilo, it is probable that $1 \mathrm{mg}$. brought about, in some instances a vagal paralysis almost but not entirely complete, and it is further likely that larger doses than those given by Lewis, Drury, Wedd and Iliescu are frequently necessary to procure complete removal of vagal tone in unanesthetized animals.

The full effect of $5 \mathrm{mg}$. was usually maintained for about 7 to 10 minutes, after which there was a gradual fall in rate. At the end 
of 35 to 40 minutes the rate was about 10 to 15 per cent lower than the maximum rate reached. When $1 \mathrm{mg}$. was used, the fall usually began within 3 to 5 minutes after the highest rate was reached, and at the end of 15 minutes the drop was definite. Table 1 illustrates a more or less typical result.

As repeated doses of $1 \mathrm{mg}$. were given, the rate usually rose to that obtained originally, but vagal tone was regained more rapidly. The maximum rate varied considerably in the same animal on different

TABLE 1

The effect of repeuted doses of $1 \mathrm{mg}$. atropine

G. 2. Resting rate 80

\begin{tabular}{c|c|c}
\hline Atropine & Time & Rate \\
\hline 1 & minutes & \\
& 1 & 224 \\
& 6 & 208 \\
$1 *$ & 15 & 184 \\
& 1 & 218 \\
& 4 & 206 \\
& 14 & 180 \\
& 1 & 208 \\
& 4 & 192 \\
& 14 & 196 \\
& 1 & 222 \\
& 3 & 206 \\
& 5 & 194 \\
\hline
\end{tabular}

* These administrations of atropine were given immediately after the last count given above.

days; thus in one dog, G2, the rates obtained on different days with $1 \mathrm{mg}$. were $204,224,232,243$. It is possible that $1 \mathrm{mg}$. did not always cause a complete paralysis of vagal inhibition in this animal, for the test of the effect of the further administration of atropine was made on only a few occasions. That an actual variation may exist, however, is shown by the fact that the injection of $4 \mathrm{mg}$. shortly after the first dose of $1 \mathrm{mg}$. failed to increase the rate above 232, although this was lower than the peak reached on another occasion, 
243. Moreover, at another time, the maximum rate after $5 \mathrm{mg}$. was $217 .{ }^{2}$

Following an injection of atropine, changes in the form of the electrocardiogram were constantly present to a greater or lesser degree. The $R$ wave was lowered, the $S$ wave deepened, and the amplitude of $T$ was increased (figs. 1 and 2).

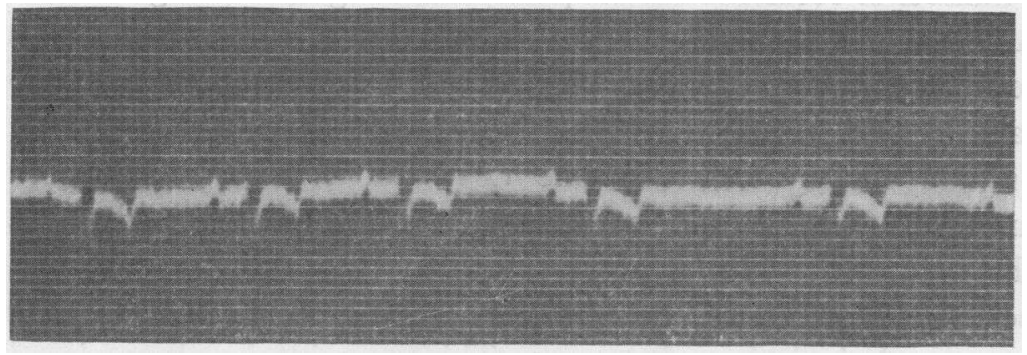

Fig. 1. The Normal Electrocardiogram of the Resting Dog (G1) Standardization in all records 1 millivolt $=1 \mathrm{~cm}$. Time lines $=0.04$ seconds

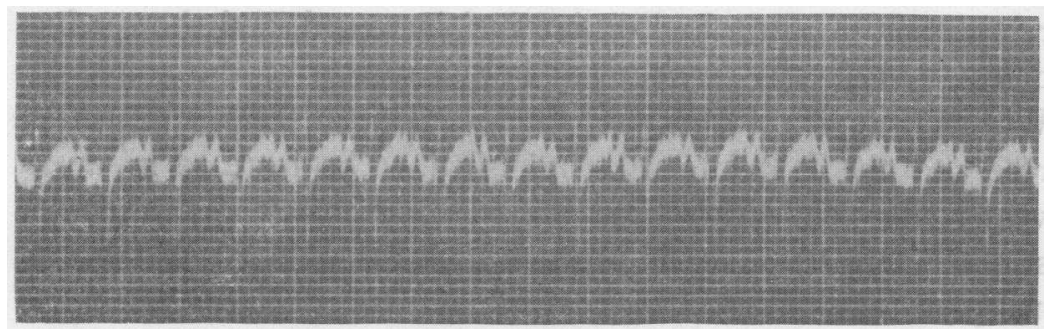

Fig. 2. Electrocardiogram Taken Shortly after the Administration OF 1 MGM. Atropine (G1)

The normal record of this animal (G3) is similar to that of figure 1

\section{The effect of pituitary extract in animals before atropine}

In three experiments $1 \mathrm{cc}$. pituitary extract was given and the results were essentially similar in each instance (table 2). Seven to

${ }^{2}$ It is not likely that variations in the potency of the drug were responsible for these discrepancies, for the atropine solutions were always made from tablets taken from the same bottle throughout the entire series of experiments. 
ten seconds after the start of the injection there was a sharp rise in rate, lasting 7 to 12 seconds. This rise was associated with a disappearance of the respiratory arrythmia commonly seen in dogs, and a decrease in the P-R interval. That this effect was not psychic and merely incidental to the insertion of the needle was proven by the fact that the injection of normal saline made in a similar manner on a number of occasions did not produce the slightest change in the rate. A similar but less marked early acceleration of rate was occasionally seen by Wiggers (1906). Following the increase, the rate slowed rapidly and within 1 to 2 minutes was considerably below the original resting rate. In one dog, G3, following the first fall in rate, there was a secondary rise of moderate degree and short duration, with a rapid return to the low rate. During the period of slowing, the beats tended to be grouped in twos, with an occasional single beat between. This grouping has been described previously by von Cyon (1898) and Garnier and Thaon (1906). The electrocardiographic curves resemble those of a rather marked degree of so-called sino-auricular block (fig. 3). With the onset of the retardation of rate, the P-R interval increased, and the conduction defect was always exaggerated in the second of the paired beats. Within 15 to 30 minutes after the injection, the heart rate gradually rose and the P-R interval diminished. The increase in auriculoventricular conduction time tended to outlast the disturbance in stimulus formation (or in intra-auricular conduction, if the view is accepted that an actual block exists between the sino-auricular node and the auricle). Upon recovery, there was no sharp transition between the stages of sino-auricular block and the usual sinus arrhythmia, and the gradual merging of the one into the other suggests an intimate relationship between the two. Excepting the change in rhythm, the most striking alteration in the electrocardiogram was a marked increase in the amplitude of the $T$ wave which occurred in all three experiments about 15 seconds after the injection of the pituitary extract. In two dogs, G1 and G2, the amplitude diminished rapidly after 30 to 45 seconds, while in the third animal the $T$ wave became lower, although it was rather high throughout the experiment.

Table 2 gives briefly the results obtained in these experiments. In figure 4 , the experiment of G1 is charted graphically. 
WILLIAM H. RESNIK AND E. M. K. GEILING
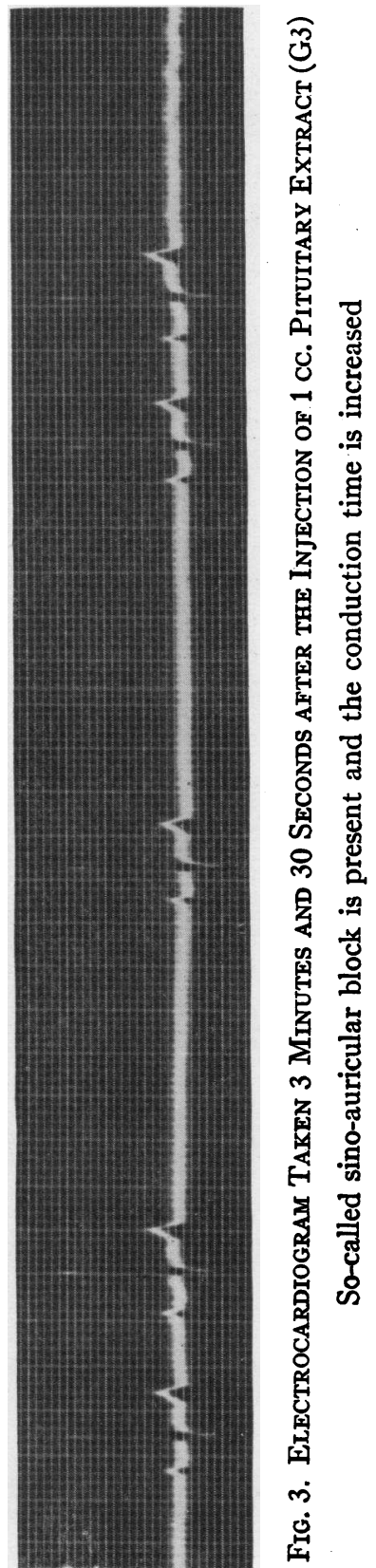


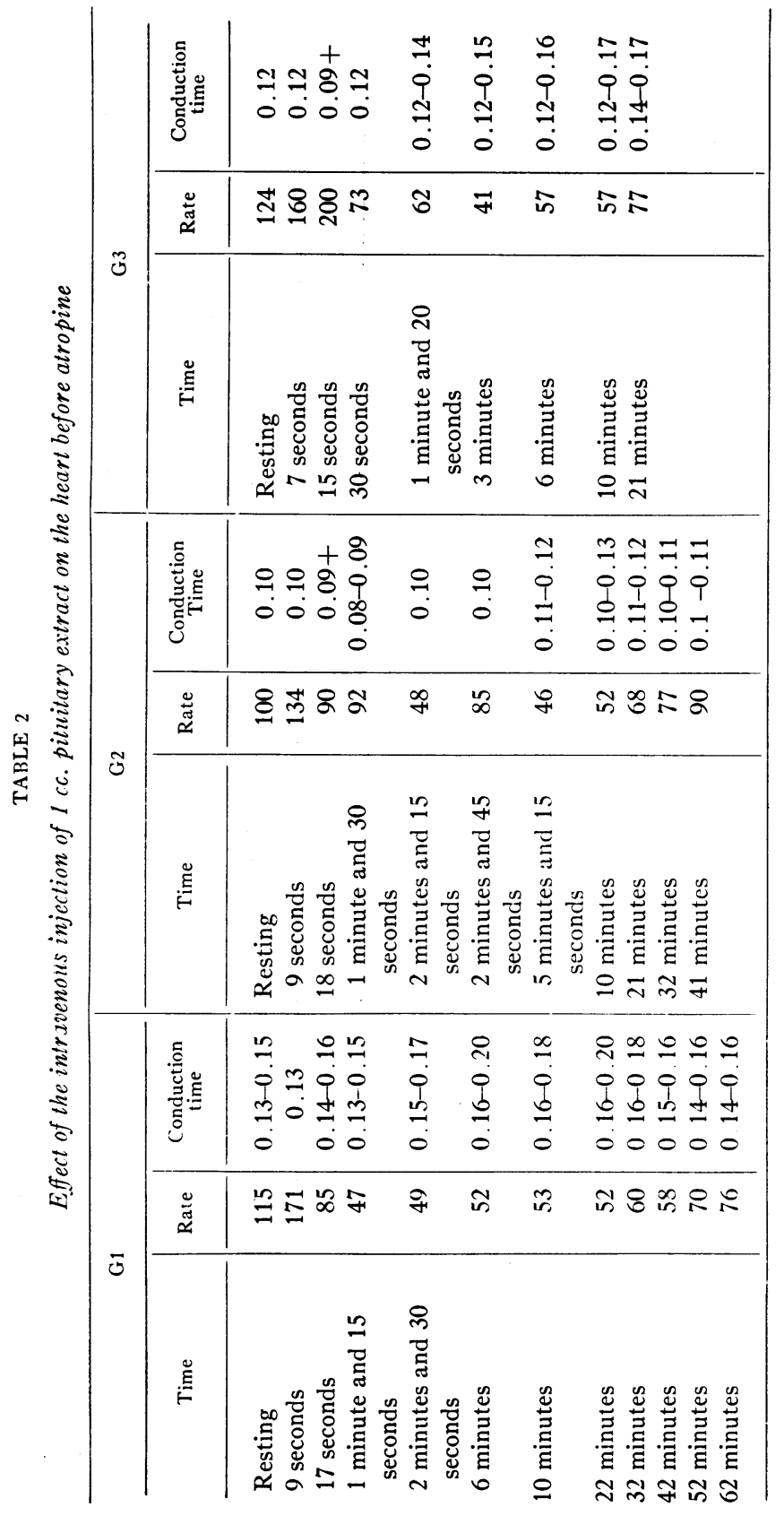


In three experiments (table 3), small amounts of pituitary extract were injected, and in these observations records were taken during only a short time, as the effect upon the period of acceleration was sought. The results were similar to those obtained with the larger dose except that they were not so marked. 'In the two experiments in which only $0.1 \mathrm{cc}$. was given, no rise in rate was seen. In one experiment, G2, in which $0.1 \mathrm{cc}$. was administered, the electrocardio-

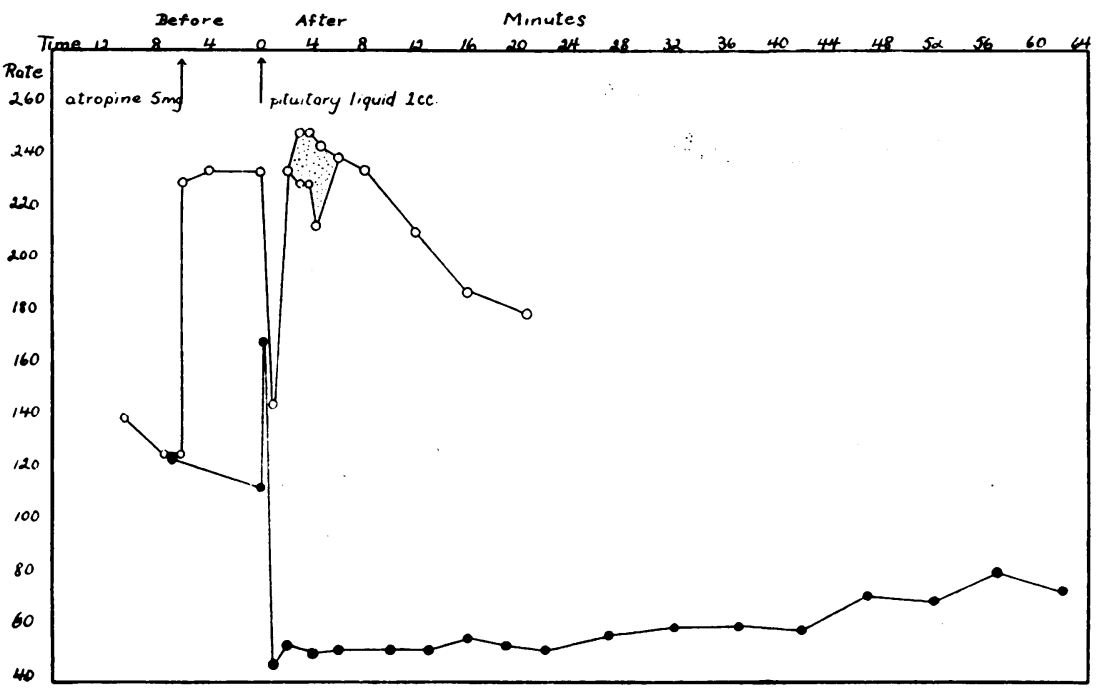

Fig. 4. The Effect of the Intravenous Injection of 1 cc. Pituitary Extract Before Atropine (LOWER CURVe) AND AFter Atropine (UPPER CURVE) Dog (G1)

The shaded area in the upper curve represents auriculo-ventricular block, the top line of this area giving the auricular and the bottom line the ventricular rates. The upper curve represents one of the few instances in which the primary rise was absent.

graphic curve taken soon after the injection showed auriculo-ventricular dissociation with an auricular rate of 38 and a ventricular rate of 39 , the idioventricular rhythm arising in the right bundle of the ventricular conduction system (fig. 5). A similar phenomenon, i.e., the dislocation of the pacemaker to one of the bundlebranches, was seen by Greeneand Gilbert (1922) in one of their experiments upon the influence of anoxemia on dogs. They attributed the disturbance in the cardiac mechanism to 

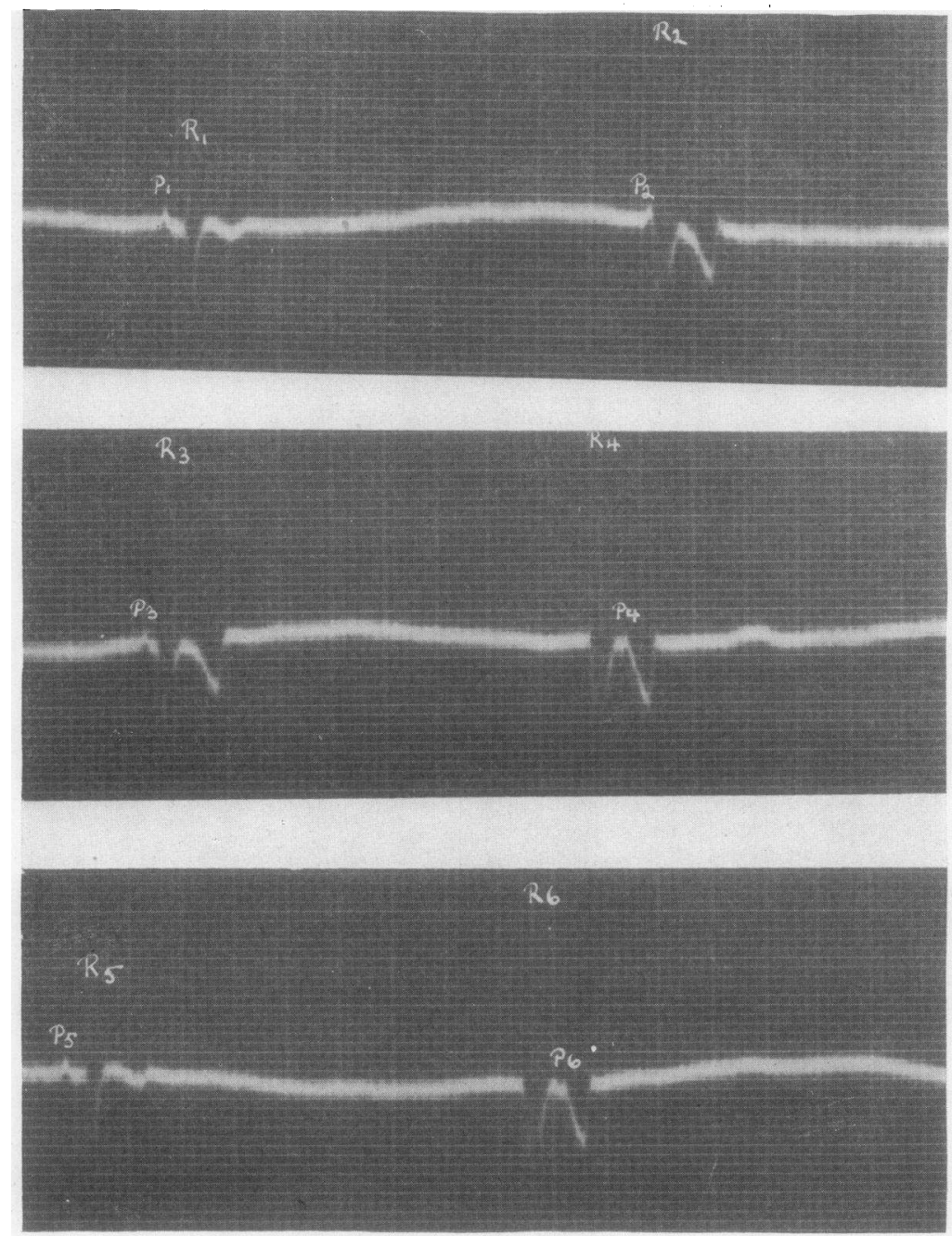

Fig. 5. Electrocardiograms Taken 1 Minute and 15 Seconds after the Injection of $0.1 \mathrm{cc}$. Pituitary Extract before

Atropine (G2)

The curve demonstrates the development of auriculo-ventricular dissociation. The three curves are continuous. In the upper record, the first ventricular complex (R1) follows an auricular impulse and has the normal supraventricular form. The second ventricular complex (R2) is idioventricular in origin, arising in the right bundle branch. In the middle record, two more ventricular beats of the same type are seen (R3 and R4). In the lower record, the first ventricular complex (R5) responds to an auricular impulse and it has the normal form. The next ventricular beat (R6) however, again arises in the right bundle branch. 
vagal stimulation, and this explanation probably holds in the instance here described. The striking increase in the amplitude of the $\mathrm{T}$ wave was absent in these experiments. In table 3 are given briefly the results of this group of observations.

\section{The effect of pituitary extract in animals after atropine}

In six experiments, $1 \mathrm{cc}$. pituitary extract was injected within 3 to 5 minutes after the administration of atropine, which in three experiments was given in single doses of $5 \mathrm{mg}$., and in three other experiments in doses of $1 \mathrm{mg}$. repeated at about 15 minute intervals (table 4). This latter method was employed in order to permit longer observations, as the animals tended to become restless after the larger amount of atropine. Very soon after the pituitary extract was given, there was a slight rise in rate which was followed rapidly by a rather marked fall of brief duration. This was succeeded by a conspicuous rise in rate which gradually and progressively fell until the close of the experiment. To facilitate the discussion of these reactions, we shall term them primary rise, primary fall, secondary rise and secondary fall respectively. In figure 4 is charted an experiment on G1. In figure 6 is shown the typical course of a longer experiment (G2).

The primary rise. In three of the experiments $(3,5,6$; table 4$)$, following the injection of pituitary extract, the rate accelerated to a level above that obtained after atropine alone. The increase was slight but definite. In a fourth experiment (4; table 4$)$, the rate had fallen rather rapidly after atropine before pituitary extract was given, and although it rose again with the administration of this drug, the level reached was below that secured with atropine alone. In two $(1,2$; table 4$)$, no change was noted. The conduction time remained the same, or increased slightly. When the rise occurred, it began 9 to 18 seconds after the injection and persisted for 8 to approximately 60 seconds.

In all these observations, a sufficient amount of time had elapsed between the injections of atropine and pituitary extract for the restoration of a certain amount of vagal tone. Three further experiments were done to eliminate any possible effect which even a slight degree 


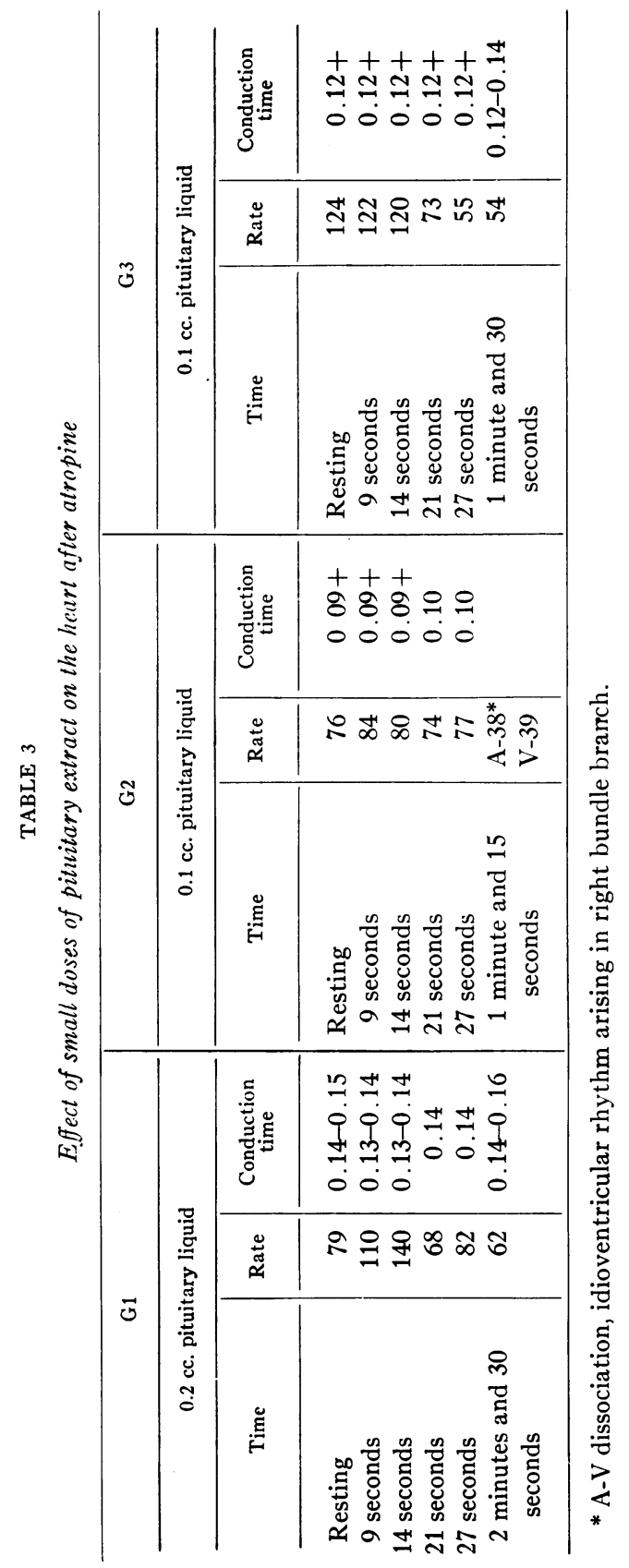




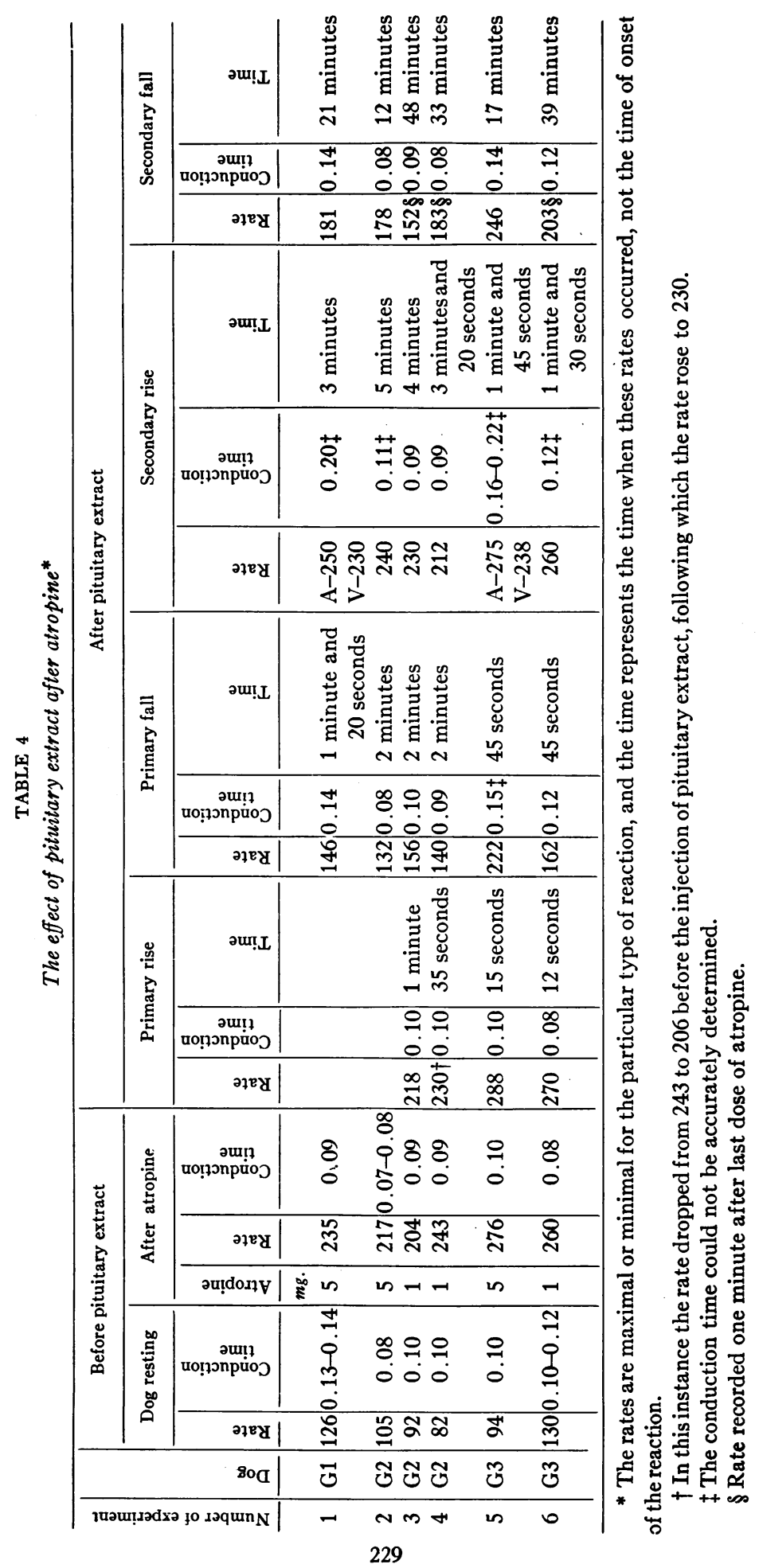


of vagal influence might have (table 5). Six milligrams of atropine were given, and one minute later, at the height of the effect, $1 \mathrm{cc}$. pituitary extract was injected. Continuous records were taken in order

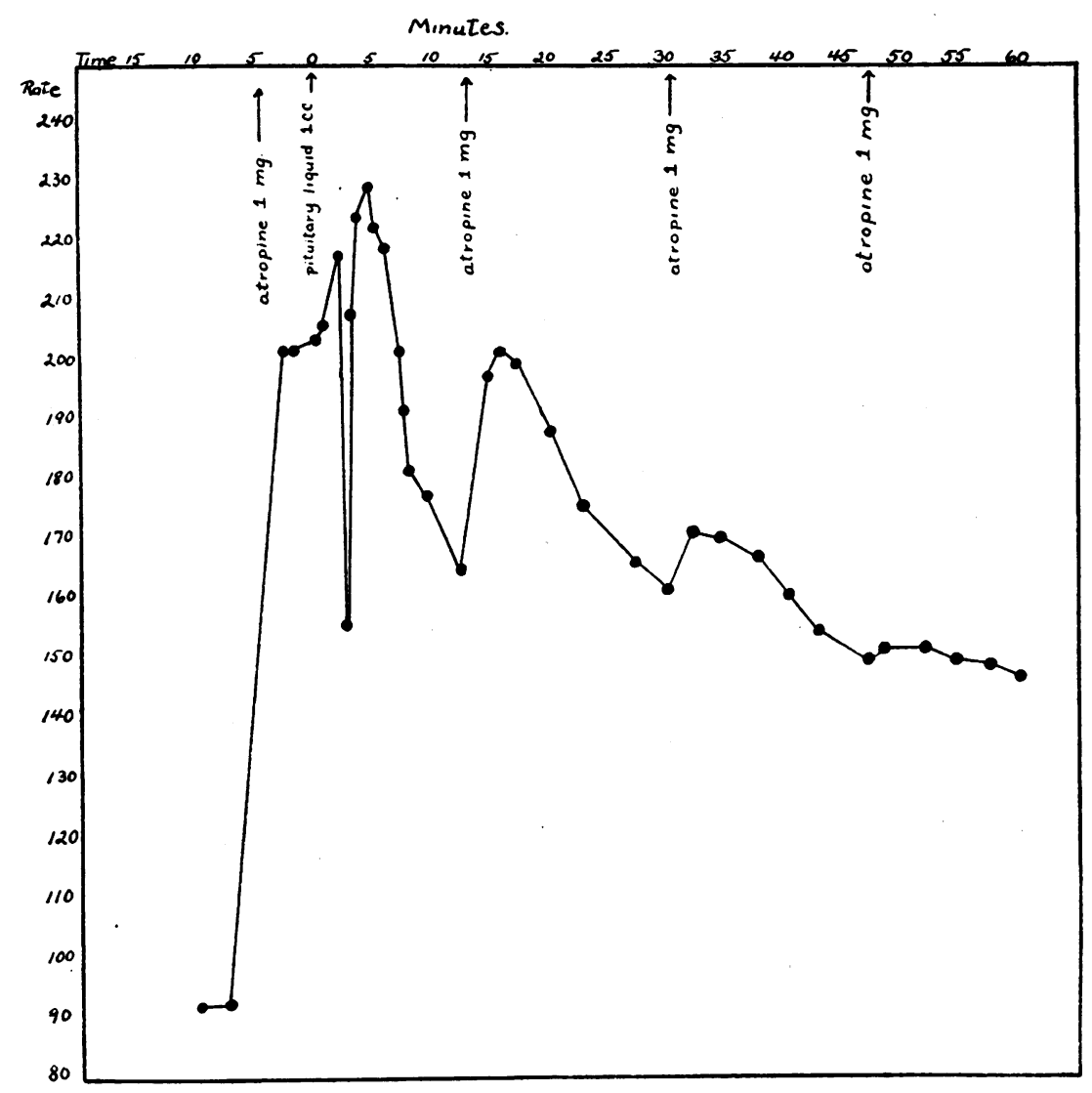

Fig. 6. The Effect of the Intravenous Injection of 1 cc. Pituitary Extract after Atropine (G2)

It demonstrates the successive stages in the typical reaction: the primary rise, the primary fall, the secondary rise and the secondary fall. The diminishing effect of atropine during the secondary fall is well shown.

that no change be overlooked. In all three, the results were strikingly constant. Eight to nine seconds after the injection, the heart rate increased, and this acceleration lasted 9 seconds in two animals and 
WILLIAM H. RESNIK AND E. M. K. GEILING

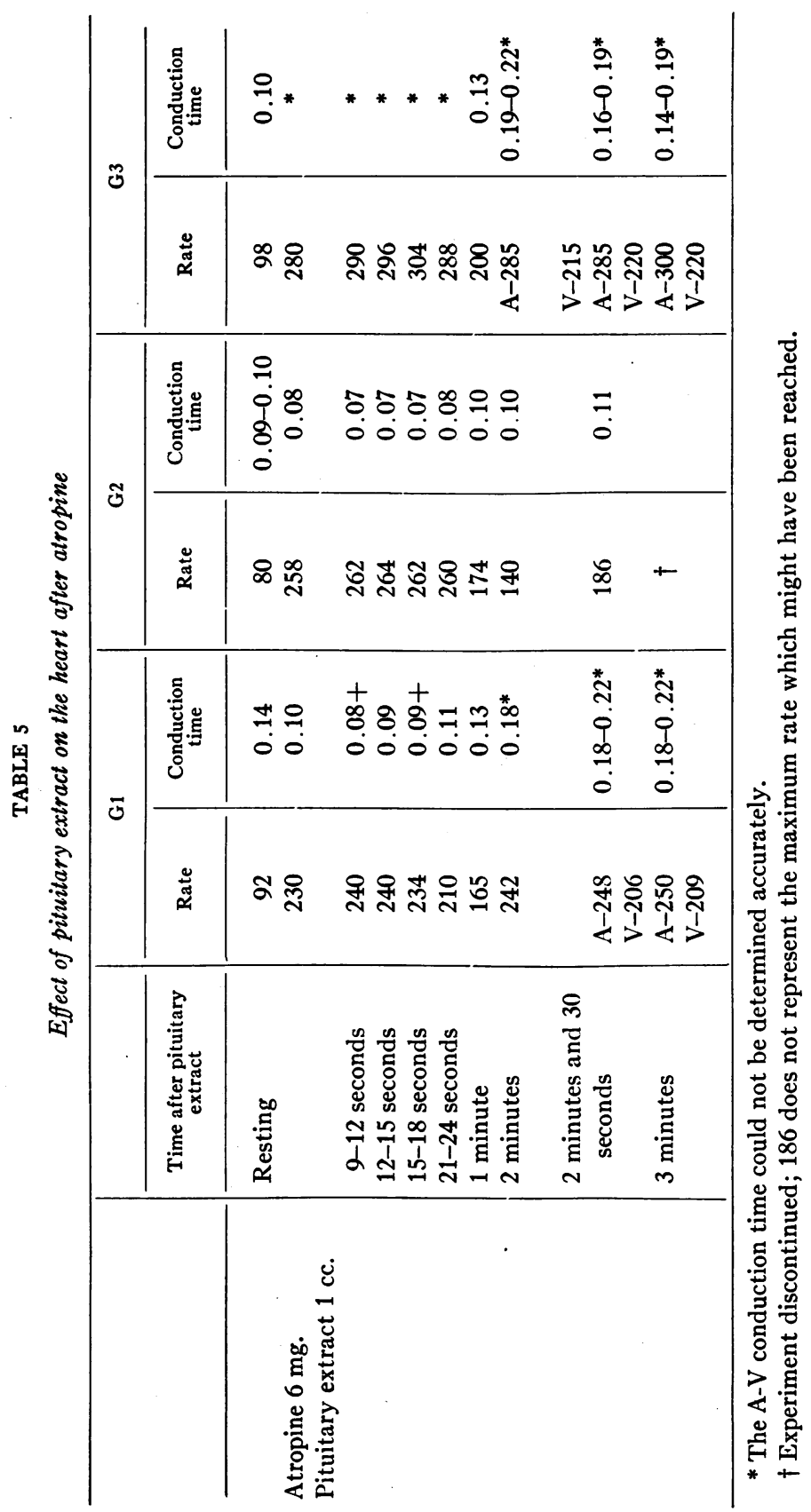


18 seconds in the third. The increased rate was now associated with a slight decrease in conduction time. Brief protocols of these three experiments are given in table 5 .

In all experiments, there was observed the same conspicuous increase in the amplitude of the $T$ wave seen previously in the animals before atropine; and the change took place almost constantly at the same time, about 15 seconds after the injection of pituitary (fig. 7). The average duration of this alteration was about 10 seconds.

The primary fall. Following the short initial rise, and in most cases about 20 seconds after the pituitary extract was given, the heart rate began to fall rather rapidly, reaching a minimum in about two minutes, sometimes earlier. The lowering was considerable, varying from

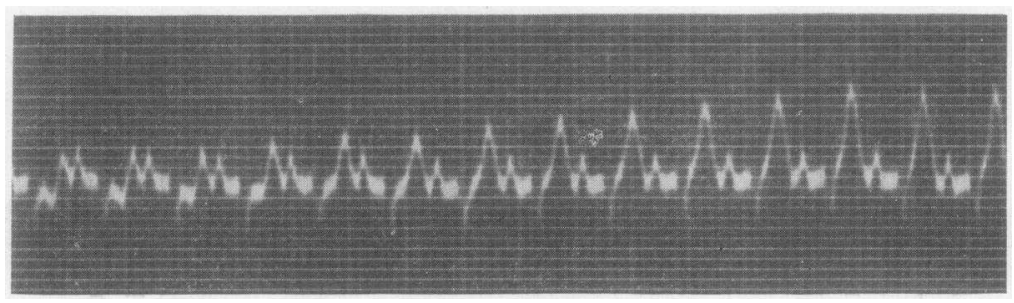

Fig. 7. Electrocardiogram Taken 15 Seconds after the Injection of 1 cc. Pituitary Extract after Atropine (G1)

Note the increasing amplitude of the $T$ wave

54 to 124 beats per minute (tables 4 and 5). At this time there was a tendency for the conduction time to increase, and in some experiments the increase was marked, but in others the change was not striking.

The secondary rise. This took place rapidly after the lowest rate was reached, and within 1 to 2 minutes the heart rate rose to a level equal to, and usually well above the maximum following atropine alone (tables 4 and 5). This marked acceleration is the more noteworthy in that it occurred when some, and often an appreciable amount of vagal tone had been regained. In all but two of the experiments, the conduction time was distinctly increased, and in four the conduction defect was sufficient to cause the dropping out of numerous ventricular beats. Erlanger and Hirschfelder (1905) and Lewis and 
Oppenheimer (1910-11) have shown that an increase in rate exaggerates depression of conduction, which in these experiments was becoming apparent in the period of primary fall.

The secondary fall. With the progress of the experiment, the heart rate gradually became slower. This change is well illustrated by figure 6 which shows the progressively diminishing effect of atropine in bringing about an increase in rate (see also table 4). With the lowering of rate the conduction time diminished, returning to normal in some cases, and remaining somewhat prolonged in others. The experiments were not continued for a sufficient length of time to determine the duration or extent of the fall in heart rate which might have taken place.

\section{DISCUSSION}

\section{The mode of action of pituitary extract upon the heart}

It is clear that the action of pituitary extract upon the heart is at least twofold: first, there is a direct action upon the myocardium which is shown by the primary and secondary falls in heart rate after vagus paralysis and which is substantiated by the concomitant depression of auriculo-ventricular conduction that occurred in most cases. Moreover, the progressive nature of the direct action is illustrated by the course of events in the more prolonged experiments in which the effect of atropine in causing an escape became less and less noticeable. Second, that pituitary extract acts through the vagi by a stimulation of the cardio-inhibitory center is demonstrated by the difference in the degree of slowing obtained in animals before and after atropine (fig. 4). The succession of events which we have observed so constantly in the experiments upon the heart after atropine has not, so far as we know, been previously described. Wiggers (1911) believes the direct action of pituitary extract on the myocardium when it occurs, is a late effect, but our results indicate, as is shown in the primary fall and the early effect upon auriculo-ventricular conduction, that pituitary extract begins to exert a depressant action on the myocardium very soon after its administration.

The direct effect upon the heart muscle is evident, but it is difficult to determine to what extent it is a primary action, or one secondary

THE JOURNAI OF CHNICAL INVEBTIGATION, VOL. I, NO. 3 
to constriction of the coronary arteries. Although Cow (1911) and Rabe (1912) were unable to demonstrate that pituitary extract exerted a consistent effect upon the coronaries, Dale (1909), Morawitz and Zahn (1914), de Bonis and Susanna (1909) and Pal (1909) have shown that the coronaries are markedly constricted by this drug.

\section{The rôle of anoxemia}

The influence of pituitary extract upon the coronaries suggests that the changes in the cardiac mechanism subsequent to the administration of this drug may be, in part at least, the expression of a reaction to an insufficient supply of oxygen. Kolls and Geiling (1924) have found recently that a few minutes after the intravenous injection of $1 \mathrm{cc}$. pituitary extract into unanesthetized dogs (the same animals used in the present series of experiments), there occurred a striking diminution in circulatory minute volume and in oxygen consumption per minute. That these effects are not merely due to a lowering of the basal metabolic rate is attested from the fact that with these changes there is seen a definite increase in the $\mathrm{H}$-ion concentration of the venous blood and a lowering of the $\mathrm{CO}_{2}$ combining power of the plasma of venous blood (Geiling), pointing to an accumulation of non-volatile acid (lactic) in the tissues. These findings are similar to those of Meakins, Dautrebande and Fetter (1923) in cases of circulatory failure and a lowering of the circulatory minute volume. Other symptoms of oxygen want appear also, such as Cheyne-Stokes respiration, and Roberts (1923) has shown in anesthetized animals that this phenomenon is due to oxygen deficiency brought about by the action of pituitary extract on the vessels supplying the medullary centers.

Greene and Gilbert (1922) studied the effect of a slowly produced, progressively increasing degree of anoxemia on the heart of the anesthetized dog. The rate increased up to a critical period (cessation of respiration), at which time the rate fell rapidly, an effect due to vagal stimulation. Before death, however, there were evidences of a direct action upon the heart muscle. Lewis and Mathison (1910-1911) investigated the effect of asphyxia in cats and found that following a short period of acceleration, the auricular rate diminished and heart 
block eventually ensued. The course of events was unaffected by vagal section, and consequently was ascribed to a direct action upon the myocardium. It is probable that the discrepancy between the results is due to the difference in the methods of producing anoxemia, and that the rapidly developed, profound degree of oxygen deficiency brought about by asphyxiation caused changes in the cardiac mechanism seen only as a late manifestation of the more slowly produced anoxemia.

The results of injection of pituitary extract resemble in some respects those obtained in both the above types of experiments. The evidence of direct action on the myocardium occurred almost from the start, and it was essentially similar to that seen by Lewis and Mathison, that is depression of conduction and slowing of the auricular rate. Actually, this direct effect appeared sooner in our experiments, and this may be due to the sudden constriction of the coronaries almost immediately after the injection. As in the experiments of Greene and Gilbert, the vagal influence was most pronounced in the earlier phases of the reaction, to be followed later by a predominantly direct action on the heart muscle. Whether anoxemia played any part in enhancing vagal tone we cannot ascertain, for the elevation of blood pressure produced by pituitary extract may in itself account for this effect. In the experiments of Greene and Gilbert and of Lewis and Mathison, there was noted the same alteration of the $T$ wave described above.

\section{The primary rise}

Although the primary rise was not constantly found, it was in most instances definite. Since it occurred after full doses of atropine as well as before atropine, vagal release may be disregarded as an explanation of the quickening of rate. Usually it occurred about 8 to 10 seconds after the injection of pituitary extract was begun, which corresponds fairly well with the amount of time necessary for the drug to reach the heart (Stewart). The rise was probably due to a direct action on the muscle, rather than to stimulation of the sympathetic nerve endings which are unaffected by pituitary extract (Dale, 1909). 


\section{The secondary rise}

This reaction usually took place at a time when a certain amount of vagal tone had been regained. Nevertheless the rate rose in most of the experiments not only to the level reached after the administration of atropine alone, but often definitely above it. There are several factors which may contribute to this acceleration and the following explanation is offered as a tentative hypothesis. The increase in systemic blood pressure reaches its height about the time when the secondary rise begins. Such an action would tend to counteract the effect of coronary constriction which is probably responsible for the primary fall. This increase in coronary flow would be further augmented by the metabolites of asphyxia (Markwalder and Starling, 1913). The increase in heart rate may be also due in part to the action of adrenal secretion which is called forth by asphyxia (Cannon, 1919). ${ }^{3}$

In only one of three animals to which $1 \mathrm{cc}$. pituitary extract had been given before atropine did an elevation of rate, corresponding to the secondary rise seen after atropine, take place. The absence of this rise was probably due to the powerful vagal stimulation which was present at the same time.

\section{SUMMARY AND CONCLUSIONS}

1. In the heart of unanesthetized dogs, pituitary extract given intravenously causes.

a. A brief period of acceleration,

b. A profound slowing with prolongation of auriculo-ventricular conduction time. During this phase, electrocardiographic curves show so-called sino-auricular block.

2. After atropine, pituitary extract brings about

Since the completion of this paper, our attention has been directed to a paper by Einis (Biochem, Ztscht., 1913, lii, 96) who observed an elevation of rate in isolated mammalian hearts about 1 to 2 minutes after the administration of pituitary extract. This would indicate that the rise in heart rate occurring at this time may be independent of the effect of blood pressure and of the action of adrenal secretion. Since Einis' results differed however from those obtained by others using isolated hearts (Hedbom, 1998; Cleghorn, 1899; Dale, 1909; Wiggers, 1911) we must await further evidence bearing upon this question. 
$a$. An early period of acceleration, followed by

b. A marked fall in rate, often associated with slight depression of auriculo-ventricular conduction. This is succeeded by

c. A conspicuous elevation of the heart rate, usually with a definite depression of auriculo-ventricular conduction. Following this there occurs

$d$. A progressive fall in rate, independent of the influence of vagal tone.

3. From the above observations, we conclude that under the conditions of our experiments, pituitary extract affects the heart

$a$. By stimulation of the vagi through the cardio-inhibitory center, and

$b$. By a direct action upon the myocardium.

c. There is possibly an indirect action on the sympathetic nerve endings during the secondary rise, through stimulation of the adrenals by asphyxia.

4. There are similarities between the effects of pituitary extract and anoxemia on the heart.

\section{BIBLIOGRAPHY}

de Bonis, V., and Susanna, V. Zentralbl. f. Physiol., 1909, xxiii, 169. ther die Wirkung des Hypophysenextraktes auf isolierte Blutgefässe.

Cannon, W. B. Amer. Jour. Physiol., 1919, 1, 399. Studies on the Conditions of Activity in Endocrine Glands.

Claude, H., Porak, R., and Routier, D. Compt. rend, Soc. de Biol., 1913, i, 996. L'action de l'extrait de lobe postérieur d'hypophyse sur la conductibilité auriculo-ventriculaire.

Cleghorn, A. Amer. Jour. Physiol., 1899, ii, 273. The Action of Animal Extracts, Bacterial Cultures, and Culture Filtrates on the Mammalian Heart Muscles.

Cow, D. Jour. Physiol., 1911, xlii, 125. Some Reactions of Surviving Arteries. von Cyon, E. Arch. f. des. ges. Physiol., 1898, lxxiii, 339. Die physiologischen Herzgifte; Hypophysenextracte.

Dale, H. H. Biochem. Jour., 1909, iv, 427. The Action of Extracts of the Pituitary Body.

Erlanger, J. and Hirschfelder, A. D. Amer. Jour. Physiol., 1905, xv, 153. Further Studies on the Physiology of Heart Block in Mammals.

Garnier, M., and Thaon, P. Jour. Physiol. et Path. gén., 1906, viii, 252. De l'action de l'hypophyse sur la pression arterielle et le rythme cardiaque.

Geiling, E. M. K. Unpublished experiments. 
Greene, C. W., and Gilbert, N. C. Amer. Jour. Physiol., 1922, 1x, 155. Studies on Responses of Circulation to Low Oxygen Tension; Cause of Changes Observed in Heart during Extreme Anoxemia.

Hecht, A. F., and Nadel, V. Wien. klin. Woch., 1913, xxvi, 1927. Experimentelle Untersuchungen über die Wirkung von Hypophysenextrackten mit Hilfe der Elektrokardiographie.

Hedbom, K. Skand. Arch. Physiol., 1898, viii, 147. Uber die Einwirkung verschiedener Stoffe auf das isolierte Säugethierherz. Erste Abhandlung. Die Einwirkung gewisser Organextracte.

Houssay, B. A. La accion fisiologica de los extractos hipofisiaros. Buenos Aires, 1918, p. 115.

Howell, W. H. Jour. Exp. Med., 1898, iii, 245. The Physiological Effects of Extracts of the Hypophysis Cerebri and Infundibular Body.

Kolls, A. C., and Geiling, E. M. K. Jour. Pharm. and Exp. Therap., 1924, xxiv, 67. Contributions to the Pharmacology of Extracts of the Posterior Lobe of the Pituitary Gland.

Lewis, T., Drury, A. N., Wedd, A. M., and Iliescu, C. C. Heart., 1921-22, ix, 207. Observations upon the Actions of Certain Drugs upon Fibrillation of the Auricles.

Lewis, T., and Mathison, G. C. Heart, 1910-11, ii, 47. Auriculo-ventricular Heart-block as a Result of Asphyxia.

Lewis, T., and Oppenheimer, B. S. Quart. Jour. Med., 1910-11, iv, 145. The Influence of Certain Factors upon Asphyxial Heart-block.

Markwalder, J., and Starling, E. H. Jour. Physiol., 1913, xlii, 275. A Note on Some Factors Which Determine Blood Flow through the Coronary Circulation.

Meakins, J., Dautrebande, L., and Fetter, W. J. Heart, 1923, x, 153. The Influence of Circulatory Disturbances on the Gaseous Exchange of the Blood. IV. The Blood Gases and Circulation Rate in Cases of Mitral Stenosis.

Morawitz, P., and Zahn, A. Deutsch. Arch. klin. Med., 1914, cxvi, $364 . \quad$ Untersuchungen über Coronarkrieslauf.

Oliver, G., and Schäfer, E. A. Jour. Physiol., 1895, xviii, 276. On the Physiological Action of Extracts of Pituitary Body and Certain Other Glandular Organs.

Pal, J. Wien. med. Woch., 1909, lix, 137. Utber die Gefässwirkung des Hypophysenextractes.

Rabe, F. Ztschr. exp. Path. u. Therap., 1912, xi, 175. Die Reaktion der Kranzgefässe auf Arzneimittel.

Roberts, F. Jour. Physiol., 1923, Ivii, 405. Action of Vaso-constrictor Sub-

1. stances on Arteries of Brain.

Schäfer, E. A., and Vincent, S. Jour. Physiol., 1900, xxv, 87. The Physiological Effects of Extracts of the Pituitary Body.

Stewart, G. N. Cited by Macleod, J. J. R. Physiology and Biochemistry in Modern Medicine, St. Louis, 4th ed., p. 214.

Wiggers, C. J. Amer. Jour. Med. Sc., 1911, cxli, 502. The Physiology of the Pituitary Gland and the Actions of Its Extracts. 